\title{
Risk Assessment Index System of Internal Control in Meteorological Department Based on AHP
}

\author{
Wu Su Zhicheng Wang Shibin Chen \\ Ezhou Meteorological Bureau , Ezhou 436000, China
}

\begin{abstract}
Risk assessment is important for internal control of administrative institutions. At present, there are few researches use risk analysis model to evaluate the risk of internal control of administrative institutions. This paper take meteorological department for example, builds risk assessment index system of internal control in meteorological department, use analytic hierarchy process to determine the weight of each index, so the index can be reasonably quantify. Through the case, preliminary discussion has been done on using risk assessment model to improve internal control of meteorological department.
\end{abstract}

\section{Keywords}

Internal Control; Risk Assessment; Analytic Hierarchy Process

\section{基于 AHP 法的基层气象部门内控 风险指标体系构建}

\author{
苏妩 王志成 陈世斌 \\ 鄂州市气象局, 鄂州 436000, 中国
}

摘要：为了有效开展行政事业单位内部控制工作，对其进行风险评估十分有必要，目前研究 以定性分析为主，应用风险分析模型对行政事业单位内部控制风险进行评估的研究不多，本 文探索应用风险模型进行行政事业单位内部控制风险评估，以基层气象部门为例，应用层次 分析法构建行政事业单位内部控制风险指标体系,使得指标能够合理量化。初步探讨将风险 评估数学模型用于基层气象部门内部控制风险评估, 提高内部控制水平。

关键词: 内部控制; 风险评估; 层次分析法

\section{1. 引言}

内部控制，是指单位为实现控制 目标，通过制定制度、实施措施和执 行程序，对经济活动的风险进行防范
和管控。内部控制是管理的重要手 段。有效的内部控制制度, 有助于提 高经营管理水平和风险防范能力，促 进可持续发展。近年来, 内部控制越 来越受到关注，在政策方面，2008 年 财政部会同证监会、审计署、银监 
会、保监会制定了《企业内部控制基 本规范》并出台了配套的指引，企业 的内部控制制度日益规范, 管理水平 有显著提高。长期以来, 行政事业单 位作为社会公共服务提供的主体，其 内部控制工作不论是在制度建设、机 制设计还是监督管理方面, 都存在着 一定程度的滞后性 ${ }^{[1]}$ 。2012 财政部制 定了《行政事业单位内部控制规范 （试行）》，自 2014 年 1 月 1 日起施 行。《行政事业单位内部控制规范 (试行)》的出台正式启动了行政事 业单位内部控制建设与实施的系统工 程, 为行政事业单位提高内部控制管 理水平提供坚实的政策理论依据。是 促进行政事业单位内部控制体系的建 立和完善, 加强廉政风险防控机制建 设的有效途径。

事业单位传统的内部控制往往重 视控制措施, 而忽略全面评估组织内 外部风险因素 ${ }^{[2]}$ 。与传统的内部控制只 注重制定控制措施不同，《行政事业 单位内部控制规范（试行）》中明确 指出单位应当建立经济活动风险定期 评估机制, 对经济活动存在的风险进 行全面、系统和客观评估。将风险评 估置于内控措施制定和执行的核心位 置, 标志着我国行政事业单位内部控 制体系建设的全方位深入开展 ${ }^{[3]}$ 。然 而, 我国内部控制工作, 特别是行政 事业单位内部控制工作起步晚，相关 人员缺乏风险评估意识, 重视程度不 足, 没有充分吸收专业人员组成风险 分析团队开展风险评估和分析。风险 意识和法制观念不够强, 部分事业单 位在强化风险意识和增强法制观念方 面还有许多工作要做, 行政事业单位 风险评估工作亟待加强。

\section{2. 层次基层气象部门内部控制风险评 估现状}

风险是与某种不利事件有关的未 来情景, 风险评估是对风险发生的强 度和形式进行评定和估计 ${ }^{[4]}$ 。具体到内 部控制风险评估是指及时识别、系统 分析组织活动中与实现内部控制目标 相关的风险, 合理确定风险应对策略 [5]。风险评估要求单位持续关注与评估 在履行行政职能过程中内部或外部因 素导致损失的可能性, 不但要关注单 位组织层级的宏观风险, 还要重视单 位业务层级的微观风险 ${ }^{[1]}$ 。

就行政事业单位而言, 单位的风 险来自于组织内部, 包括经营管理、 项目建设、人事变动等, 另外也来自 于外部风险, 通常有外部环境变动、 政策改变等 ${ }^{[2]}$ 。对于风险评估, 现有研 究多从定性角度探讨风险的识别以及 风险的应对措施 ${ }^{[-8]}$, 相较企业, 应用 风险分析模型对行政事业单位内部控 制风险进行定量评估的研究不多。

气象部门实行统一领导, 分级管 理, 以气象部门为主, 部门与地方政 府双重领导的管理体制, 预算由中央 和地方双方共同负责安排, 财务管理 体制特殊性带来内部控制管理的难度 [9]。在《行政事业单位内部控制规范 (试行)》出台后, 中国气象局相继 出台了一系列政策, 为气象部门的内 部控制管理工作开展提供了可行规 范, 对气象部门构建符合单位实际的 内部控制体系提供了依据, 各级气象 部门加强了单位的内部控制工作, 气 象部门的内部控制工作有了长足的进 步。然而基层气象部门存在会计人员 多为兼职, 一般从业务人员中产生, 对财经法律、法规及财务知识的了解 不充分、不透彻, 内部控制意识淡 薄, 对各种风险认识不足等问题 ${ }^{10]}$ 。 从防控风险层面上来看, 气象部门管 理层风险意识逐渐加强, 但各单位尚 未建立经济活动风险评估制度和解决 方法, 也未成立风险评估工作小组, 对经济活动存在风险缺乏全面、系统 
和客观评价 ${ }^{[9]}$ ，完善内部控制特别是建 立经济活动风险评估制度显得尤为重 要。

本研究拟将风险评估经典模型引 入行政事业单位内部控制风险评估, 以基层气象部门为例探索应用层次分 析法构建行政事业单位内部控制风险 评估指标体系。

\section{3. 层次分析法简介}

层次分析法（AHP）是对定性问 题进行定量分析的一种简便、灵活而 又实用的多准则决策方法，在企业与 行政事业内部控制评价中有广泛的应 用, 周翔 ${ }^{[11]}$ 、唐勇军 [12]等将 AHP 应用 于人民银行内部控制相关研究, 赵福 荣 ${ }^{[13]}$ 将 AHP 应用于公立医院内部控制 有效性评价体系构建, 孙志梅等 ${ }^{[14]}$ 将 AHP 应用于国有企业内部控制评价指 标体系构建, 陈艳等 ${ }^{[15]}$ 基于 AHP 与 FCE 的视角构建行政事业单位内部控 制有效性评价框架。

层次分析法的特点是把复杂问题 中的各种因素通过划分为相互联系的 有序层次，使之条理化，根据对一定 客观现实的主观判断结构（主要是两 两比较) 把专家意见和分析者的客观 判断结果直接而有效地结合起来, 将 一层次元素两两比较的重要性进行定 量描述。而后, 利用数学方法计算反 映每一层次元素的相对重要性次序的 权值, 通过所有层次之间的总排序计 算所有元素的相对权重并进行排序。

层次分析法将无结构复杂系统结 构化, 通过层次内两两比较和层次间 权重解决了多因素、主观判断的不可 公度问题, 实现定性和定量相结合, 通过一致性检验一定程度上解决主观 判断的可靠性问题，提高主观决策过 程的科学性, 是分析多目标、多因 素、多准则复杂大系统的有力工具 [16]。

\section{4. 指标体系构建}

层次分析法的第一步是建立递阶 层次结构, 按照要素性质分类并建立 层次关系, 上一层要素支配下一层要 素。本文根据基层气象部门内控常见 风险点构建立递阶层次结构（图 1）。 第一、二层为目标层, 分为总目标层 和子目标层。总目标层即行政事业单 位内部控制风险评估的状况, 总目标 的实现取决于单位层面的风险与业务 层面的风险两项子目标的实现程度。 第三层为准则层, 单位层面包括内部 控制领导小组风险、集体议事决策制 度风险、关键岗位管理制度风险、会 计机构管理制度风险等 4 个三级指 标, 业务层面风险从 6 个方面进行设 定，包括预算业务控制风险、财务收 支业务控制风险、政府采购业务控制 风险、资产业务控制风险、建设项目 业务控制风险、合同业务控制风险。 第四层为指标层, 包括议事成员构成 风险等 32 个指标。

在构建了递阶层次结构后需要构 造两两比较判断矩阵 $\mathrm{A}$

$$
A=\left\{\begin{array}{c|ccc}
1 & a_{12} & \cdots & a_{1 n} \\
a_{21} & 1 & \cdots & x_{2 n} \\
\cdots & \cdots & \cdots & \cdots \\
a_{n 1} & \cdots & \cdots & 1
\end{array}\right\}
$$

判断矩阵和相对权重计算是由定 性过渡到定量的核心, 决定综合评估 的科学性。 


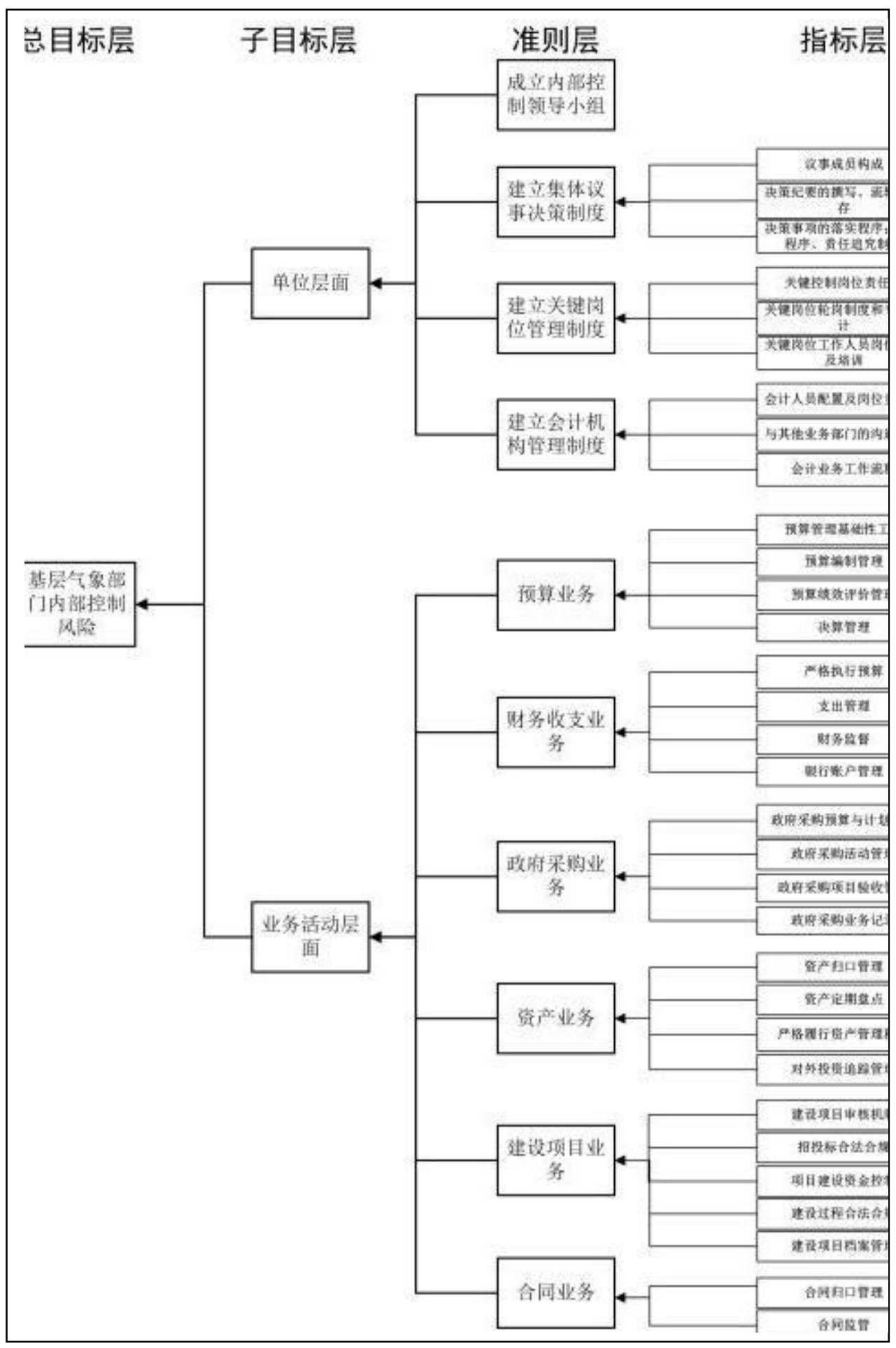


判断矩阵和相对权重确定, 层次 分析法常用 9 级标度法, 通过专家评 议对各个层次内要素进行重要性程度 赋值, 建立各层指标的判断矩阵, 要 素 $\mathrm{i}$ 与要素 $\mathrm{j}$ 重要性比较结果如表 1 :

\section{5. 结论和展望}

本文探索了应用风险模型进行行 政事业单位内部控制风险评估，根据 《行政事业单位内部控制规范（试

表 1 1-9 标度表

\begin{tabular}{|c|c|}
\hline 标度 & 含义(两个指标的相对重要性的比较) \\
\hline 1 & 表示两个要素相比, 具有同样重要性 \\
\hline 3 & 表示两个要素相比, 前者比后者略微重要 \\
\hline 5 & 表示两个要素相比, 前者比后者明显重要 \\
\hline 7 & 表示两个要素相比, 前者比后者强烈重要 \\
\hline 9 & 表示两个要素相比, 前者比后者绝对重要 \\
\hline $2,4,6,8$ & 介于相邻判断值之间 \\
\hline 倒数 & $\begin{array}{l}\text { 若要素 } \mathrm{i} \text { 与要素 } j \text { 的重要性之比为 } a_{i j} \text { 那么要素 } j \text { 与要素 } i \text { 的重 } \\
\text { 要性之比为 } \\
a_{j i}=1 / a_{i j}\end{array}$ \\
\hline
\end{tabular}

通过两两比较, 确定了判断矩阵 及各个层次内要素的重要性强弱后, 需要对各指标的权重加以计算, 以明 确各指标对内部控制有效性评价的重 要程度。权重的计算方法有和法、根 法和特征根法等。其中特征根法应用 最广泛且操作简单。由于判断矩阵的 各个重要性因素是根据专家主观经验 得到的, 考虑到内控风险评估的复杂 性、评价专家认知的多样性, 两两比 较指标可能得出不一致的矛盾结论。 比如, 指标 $\mathrm{i}, \mathrm{j}, \mathrm{k}$ 重要性相对接近, 在专家评判时会出现 $\mathrm{i}$ 比 $\mathrm{j}$ 重要, $\mathrm{j}$ 比 $\mathrm{k}$ 重要, 而 $\mathrm{k}$ 又比 $\mathrm{i}$ 重要的情况。为避免 错误, 需要对判断矩阵进行一致性检 验。只有通过一致性检验, 才能确认 判断矩阵在逻辑上是合理的。一致性 检验一般是通过计算一致性比例值确 定一致性程度, 如没有通过一致性检 验, 则需要对判断矩阵进行调整, 直 至得出满意的一致性。
行）》以及气象部门内部控制常见风 险点, 选取了符合基层气象部门内部 控制风险评估指标，采用层次分析 法, 构建一个能够从整体上反映基层 气象部门内部控制风险评估指标体系 框架, 以期对基层气象部门内部控制 风险点进行有效防控, 提高基层气象 部门内部控制水平, 探索风险评估模 型在行政事业单位内部控制风险评估 的应用。然而, 本文的指标体系尚需 从实证研究的角度在实际工作中根据 不同单位的特点和业务范围不断加以 调整和完善。同时, 还可以探索其他 定量风险评估模型在行政事业单位内 部控制中的应用。

\section{参考文献}

[1] 刘永泽, 唐大鹏. 关于行政事业单 位内部控制的几个问题. 会计研究, 2013, (01): 57-62.

[2] 梁伦泉. 以风险识别与评估为导向 的事业单位内部控制现状及对策. 
行政事业资产与财务, 2016, (04): 41-42.

[3] 张洁. 谈行政事业单位内部控制体 系的核心-—风险评估. 经济师, 2015, (09): 129-131.

[4] 黄崇福. 自然灾害风险分析与管理. 北京: 科学出版社, 2012.

[5] 胡艳琴. 如何学习行政事业单位内 部控制中的风险评估. 现代经济信 息, 2013, (08): 106.

[6] 佟淑灵. 浅析行政事业单位的内部 控制与风险评估. 经贸实践, 2017, (13): 89.

[7] 吴丽娜. 浅谈行政事业单位的风险 评估与内部控制方法. 宿州教育学 院学报, 2014, (03): 59-61.

[8] 郑姝. 浅谈风险导向型行政事业单 位内部控制体系的构建. 企业导报, 2016, (17): 155.

[9] 詹敏. 关于气象部门内部控制的几 点思考. 行政事业资产与财务, 2014, (33): 126-127.

[10] 刘德菊, 田雨. 基层气象部门实行 内部控制规范的思考. 财会研究, 2014, (06): 69-71.

[11] 周翔, 姜静敏. 基于 AHP 的人民 银行内部控制评价. 河南工程学院 学报 (社会科学版) , 2010, 25(1): 36-40.

[12] 唐勇军, 沈惠文. 基于 AHP 的人 民银行内部控制项目评价研究. 重 庆理工大学学报(自然科学), 2014, (11): 121-126.

[13] 赵福荣. 基于 AHP 的公立医院内 部控制有效性评价体系构建. 财会 通讯, 2016, (29): 111-114.

[14] 孙志梅, 李秀莲, 王昕. 基于 AHP 法的国有企业内部控制评价指标体 系构建. 财会通讯, 2012, (19): 23-25.

[15] 陈艳, 于洪鉴, 衣晓青. 行政事业 单位内部控制有效性评价框架研 究——基于 AHP 与 FCE 的视角. 财经问题研究, 2015, (09): 72-79.

[16] 韩传模, 汪士果. 基于 AHP 的企
业内部控制模糊综合评价. 会计研 究, 2009, (04): 55-61. 